\title{
Influence of Membrane-Fusogen Distance on the Secondary Structure of Fusogenic Coiled Coil Peptides
}

\author{
Geert A. Daudey," Christian Schwieger, ${ }^{\ddagger}$ Martin Rabe, ${ }^{\S}$ and Alexander Kros, ${ }^{* \dagger \odot}$ \\ ${ }^{\dagger}$ Supramolecular and Biomaterials Chemistry, Leiden Institute of Chemistry, Leiden University, P.O. Box 9502, 2300 RA Leiden, \\ The Netherlands \\ ${ }^{\ddagger}$ Martin-Luther-Universität Halle-Wittenberg, 06099 Halle (Saale), Germany \\ ${ }^{\S}$ Department of Interface Chemistry and Surface Engineering, Max-Planck-Institut für Eisenforschung GmbH, 40237 Düsseldorf, \\ Germany
}

\section{Supporting Information}

ABSTRACT: Liposomal membrane fusion is an important tool to study complex biological fusion mechanisms. We use lipidated derivatives of the specific heterodimeric coiled coil pair E: (EIAALEK) ${ }_{3}$ and K: (KIAALKE) ${ }_{3}$ to study and control the fusion of liposomes. In this model system, peptides are tethered to their liposomes via a poly(ethylene glycol) (PEG) spacer and a lipid anchor. The efficiency of the fusion mechanism and function of the peptides is highly affected by the PEG-spacer length and the lipid anchor type. Here, the influence of membrane-fusogen distance on the peptide-membrane interactions and the peptide secondary structures is studied with Langmuir film balance and infrared reflection absorption spectroscopy. We found that the introduction of a spacer to monolayer-tethered peptide $\mathrm{E}$ changes its conformation from solvated random coils to homo-oligomers. In contrast, the described peptide-monolayer interaction of peptide $\mathrm{K}$ is not affected by the PEG-spacer length. Furthermore,

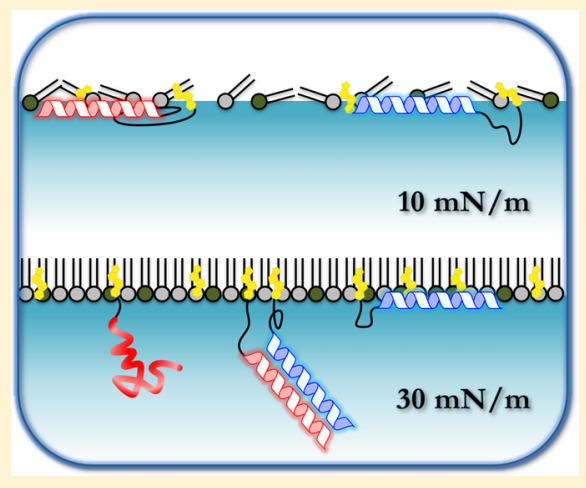
the coexistence of different conformations when both lipopeptides $\mathrm{E}$ and $\mathrm{K}$ are present at the membrane surface is demonstrated empirically, which has many implications for the design of effective fusogenic recognition units and the field of artificial membrane fusion.

\section{INTRODUCTION}

Natural membrane fusion is a key process for cellular logistics and signaling. Thus, it has been extensively studied for decades. Although the overall process of membrane fusion is well understood, ${ }^{1-3}$ mechanisms at the molecular level still are a matter of debate due to the intrinsic complexity of biological systems. To promote the understanding of the naturally occurring fusion machinery ${ }^{4-8}$ and to identify important parameters in such mechanisms, a variety of functional mimics were developed recently. ${ }^{9-13}$ In our group, we employed the lipidated heterodimeric coiled coil pair E (EIAALEK) 3 and $\mathrm{K}$ (KIAALKE) ${ }_{3}$ as a molecular recognition motif and fusogen. The peptides are held in lipid membranes by a lipid anchor, either cholesterol (C) or 1,2-dioleoyl-sn-glycero-3-phosphoethanolamine (DOPE), (L), and this is conjugated to the peptide via a poly(ethylene glycol) (PEG)-spacer of variable length $n$ to yield $\mathrm{C} / \mathrm{LP}_{n} \mathrm{E}$ and $\mathrm{C} / \mathrm{LP}_{n} \mathrm{~K}$. The ability of these lipopeptides to effectively mediate liposomal fusion both in vitro and in vivo has been shown in several papers. ${ }^{14-17}$

In these studies, coiled coil formation between $\mathrm{E}$ and $\mathrm{K}$ was thought to initiate the fusion of the bilayers. However, it was demonstrated recently that peptide $\mathrm{K}$ can insert into the lipid membrane because of the amphipathic nature of its $\alpha$ helix. $^{22,33}$ Peptide $\mathrm{K}$ orients its helix axis parallel to the monolayer surface with the hydrophobic moment of the $\alpha$ - helix pointing toward the hydrophobic part of the monolayer. It is anticipated that $\mathrm{K}$ interacts with the negatively charged phosphate moieties of the phospholipids via "snorkeling" its positively charged Lys residues toward the polar region of the bilayer. The membrane insertion of peptide $\mathrm{K}$ may locally disrupt the uniformity of the membrane in its proximity, promoting the formation of protrusions. It is hypothesized that such protrusions are a fundamental step in the merging of opposing membranes in the fusion process. ${ }^{18}$

Until now, the conformation of peptides $\mathrm{E}$ and $\mathrm{K}$ on membrane surfaces was studied using $\mathrm{LP}_{12}$-functionalized derivatives, because significant fusion efficiency was obtained when liposomes were functionalized with these peptides. However, liposome fusion mediated by cholesterol-anchored peptides $\mathrm{CP}_{12} \mathrm{E} / \mathrm{CP}_{12} \mathrm{~K}$ is twice as efficient compared with DOPE-anchored derivatives, ${ }^{19}$ which raised interest in the influence of the anchor on the peptide dynamics. Furthermore, it was recently found that the membrane-fusogen distance, as defined by PEG spacer length, is crucial for efficient fusion and the highest fusion efficiency was obtained with $\mathrm{CP}_{12} \mathrm{E}$ and $\mathrm{CP}_{8} \mathrm{~K}^{20}$ Measuring the dependency of the $\mathrm{CP}_{n} \mathrm{E}$ and $\mathrm{CP}_{n} \mathrm{~K}$

Received: December 18, 2018

Revised: March 18, 2019

Published: March 25, 2019 
fusion efficiency on $n$ revealed the distinct asymmetric roles of both peptides in the fusion process (Figure 1). Liposome-

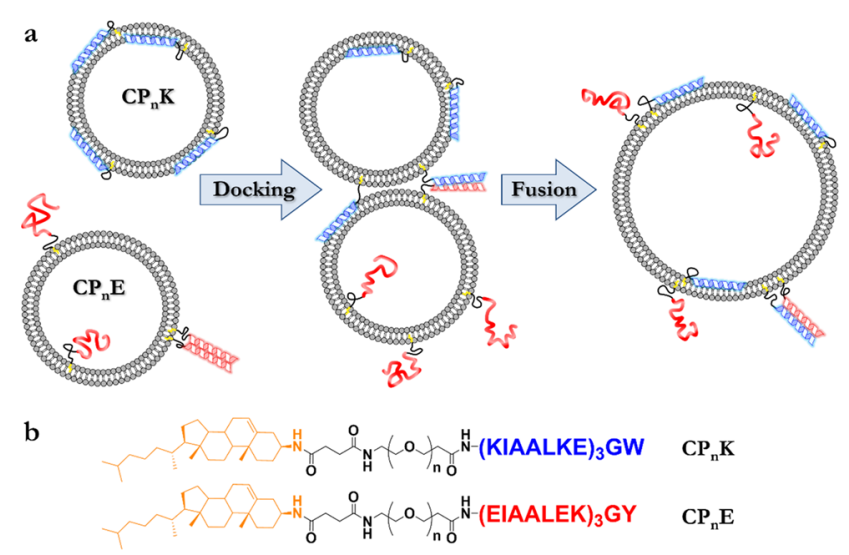

Figure 1. Schematic representation of the liposomal fusion process with fusogenic lipopeptides $\mathrm{CP}_{n} \mathrm{~K}$ and $\mathrm{CP}_{n} \mathrm{E}$. (a) Coiled coil formation of complementary lipopeptides forces individual liposomes in close proximity and concomitant fusion. (b) PEG-spacers were comprised of $n$ repeating units of ethylene glycol, with $n=0,4,8,12$, and 16. A succinic acid moiety was used to conjugate cholesterolanchor and PEG-spacer.

tethered peptide $\mathrm{E}$ is thought to act as a handle to enable docking of peptide $\mathrm{K}$ decorated liposomes, with the effectivity of this handle being enhanced by elongated spacers. After docking, the fusion process is dictated by peptide $\mathrm{K}$ via incorporation into both opposing liposomal membranes, which destabilizes both lipid membranes and promotes the formation of fusion intermediates. ${ }^{18}$

The results suggested that equilibria between these multiple peptide interactions in the docking state are affected by the anchor type and PEG-spacer length of the utilized lipopeptides. Furthermore, it is anticipated that the incorporation of $\mathrm{CP}_{n} \mathrm{~K}$ in the opposing liposomal membrane is crucial for efficient fusion. It is hypothesized that this highly dynamic docking state is rate-limiting the fusion cascade.

Here, we study the influence of the membrane-fusogen distance on the peptide structure and the peptide-membrane interaction. A systematic variation of $\mathrm{CP}_{n} \mathrm{E}$ and $\mathrm{CP}_{n} \mathrm{~K}$ was used by varying the length of the PEG-spacer from 0 to 16 monomers in steps of 4 monomers. ${ }^{20}$ The ability of the peptide to immerse into a lipid monolayer was measured by the Langmuir film balance, whereas IRRA spectroscopy was used to determine the peptide orientation with respect to the monolayer and the solvent exposure of the peptide bonds. The results found for $\mathrm{CP}_{12} \mathrm{E} / \mathrm{CP}_{12} \mathrm{~K}$ are compared with the results reported for $\mathrm{LP}_{12} \mathrm{E} / \mathrm{LP}_{12} \mathrm{~K}$ derivatives to assess the influence of the anchor on the peptide structure.

\section{EXPERIMENTAL SECTION}

Materials. (DOPC), 1,2-dioleoyl-sn-glycero-3-phosphoethanolamine (DOPE), and cholesterol were purchased from Avanti Polar Lipids. Chloroform, methanol (both high-performance liquid chromatography (HPLC) grade), $\mathrm{D}_{2} \mathrm{O}$ (99.9\% deuterium content), buffer salts, and $\mathrm{HCl}$ and $\mathrm{DCl}(99 \%$ deuterium content) for $\mathrm{pH} / \mathrm{pD}$ adjustment were purchased from Sigma-Aldrich. All water was ultrapure with resistance $\geq 18 \mathrm{M} \Omega$ and TOC $\leq 2 \mathrm{ppm}$ produced from a Milli-Q Reference A+ purification system. All monolayer and IR experiments were carried out in phosphate buffered saline of the following composition: $150 \mathrm{mM} \mathrm{NaCl}, 20 \mathrm{mM} \mathrm{PO}_{4}{ }^{3-}$ in $\mathrm{H}_{2} \mathrm{O}$ (phosphate-buffered saline, $\mathrm{PBS}$ ) or $\mathrm{D}_{2} \mathrm{O}$ (d-PBS) at $\mathrm{pH} / \mathrm{pD} 7.4$, respectively.

Calculation of Lipopeptide Dimensions. To estimate the dimensions of the used lipopeptides, we assumed stiff rod models for both peptide and PEG components. Since the movement of lipopeptides at monolayers is regarded as predominantly twodimensional, bending of the linear molecule will not alter the occupied surface area significantly. Peptide helices have a diameter of $10 \AA$, 3.6 residues per turn, and a pitch of $5.1 \AA$ A This gives a peptide length of $34.5 \AA$ for 23 residues. The PEG length is estimated via calculation of the stretched end-to-end distance of the PEG-chain in ChemDraw, which yielded an average length of $3.6 \AA$ per ethylene glycol unit. The length of the succinimide moiety is comparable to one unit of ethylene glycol and covered by the factor $n+1$. A diameter of $4.15 \AA$ is found for any primary alkyl chain and is a good approximation of the diameter of a poly(ethylene glycol) chain.

Monolayer Preparation. Lipid solutions of DOPC/DOPE/ cholesterol as 2:1:1 $(c=1 \mathrm{mM})$ with 0 or $4 \mathrm{~mol} \%$ lipopeptides were prepared in $\mathrm{CHCl}_{3} / \mathrm{CH}_{3} \mathrm{OH}$ 3:1 vol \%. For the preparation of a lipid monolayer, a distinct volume of these solutions was spread on PBS buffer at $25{ }^{\circ} \mathrm{C}$ by means of a microliter syringe; the solvent was allowed to evaporate, and the film to equilibrate for at least $15 \mathrm{~min}$. A microbalance was used for surface pressure measurements using a filter paper as a pressure probe.

Initial cleaning of the troughs was achieved by means of a diluted detergent solution (2\% Hellmanex (Hellma Analytics, Müllheim, Germany) in $\mathrm{H}_{2} \mathrm{O}$ ), followed by extensive rinsing with $\sim 50{ }^{\circ} \mathrm{C}$ MilliQ water, wiping with $\mathrm{CHCl}_{3} / \mathrm{MeOH}$, and finally multiple rinsing with Milli-Q water. All Langmuir trough setups were held constant at 25 ${ }^{\circ} \mathrm{C}$ by means of a circulating water bath and were isolated from the environment by plastic covers.

Compression-Expansion Cycles. For compression-expansion cycles of lipid monolayers containing monolayer-tethered peptides $\mathrm{CP}_{n} \mathrm{E}$ and/or $\mathrm{CP}_{n} \mathrm{~K}$, monolayers on PBS were prepared. After equilibration, compression-expansion cycles of the monolayer were performed with a compression/expansion speed of $3 \AA^{2} /$ (molecule $\mathrm{min}$ ), and experiments were repeated twice to ensure reproducibility of the isotherm shape. For determination of lateral compressibility, compression isotherms over a surface pressures, $0-30 \mathrm{mN} / \mathrm{m}$, were smoothed by means of an adjacent average method and the film compressibility $\left(C_{S}\right)$ was calculated as

$$
C_{\mathrm{S}}=\frac{-1}{A}\left(\frac{\partial A}{\partial \pi}\right)_{T}
$$

with molecular area $A$ and surface pressure $\pi$.

Infrared Reflection Absorption Spectroscopy (IRRAS) Measurements. IRRAS measurements were performed on a BRUKER Vector 70 FT-IR spectrometer equipped with a nitrogencooled MCT detector and an A511 reflection unit (Bruker Optics, Germany), placed over the Langmuir trough setup (Riegler \& Kierstein, Germany). The sample trough $\left(30 \times 6 \mathrm{~cm}^{2}\right)$ was equipped with a Wilhelmy balance using a filter paper as the pressure probe. A circular reference trough $(r=3 \mathrm{~cm})$ placed next to the sample trough can be brought into the focus of the IR beam by means of a shuttle. The filling levels of both troughs were kept equal and constant by means of an automated, laser-reflection controlled pumping system connected to reservoirs of $\mathrm{D}_{2} \mathrm{O}$. Lipid monolayers containing the lipopeptides were prepared as described above, on a subphase of $d$ PBS. The $\mathrm{pD}$ was set to 7.4 by adding 0.4 to the readout of a standard pH-meter. ${ }^{21}$ IRRA spectra were recorded at constant surface pressures below $(10 \mathrm{mN} / \mathrm{m})$ and above $(30 \mathrm{mN} / \mathrm{m})$, the expected squeeze out pressure of the peptides.

\section{RESULTS AND DISCUSSION}

Design of the Study. A PEG series $\mathrm{P}_{n}$ was used with 0,4 , 8,12 , and 16 units of ethylene glycol, and cholesterol was used as the anchor moiety. ${ }^{15}$ The molecular structures and used peptide sequences are shown in Figure 1. Peptides were 
synthesized with automated solid-phase peptide synthesis using Fmoc chemistry, and after coupling of the final amino acid, the PEG component and the anchor moiety were coupled. The lipopeptides were cleaved from the resin and subsequently purified using reverse-phase chromatography yielding purities $>95 \%$. Details of the synthetic procedures are described elsewhere. ${ }^{20}$

E/K-Membrane Interaction by a Langmuir Film Balance. The interactions of the various $\mathrm{CP}_{n} \mathrm{E}$ and $\mathrm{CP}_{n} \mathrm{~K}$ derivatives with membranes were investigated by compression isotherms of lipid monolayers functionalized with peptides. Monolayers with $4 \%$ lipopeptide were prepared on PBS $\mathrm{pH}$ 7.4 , and the surface pressure $(\pi)$ was measured as a function of the molecular area $(A)$ during compression and expansion of the monolayer. The $\pi / A$ isotherm of the pure lipid mixture (DOPC/DOPE/cholesterol as 2:1:1) showed no irregularities, such as plateaus or break points, which is consistent with monolayers in a liquid expanded state without phase transitions. With lipopeptides tethered to the monolayer, all $\pi / A$ isotherms showed higher molecular areas at low pressures $(0-15 \mathrm{mN} / \mathrm{m})$ compared with the isotherm of the pure lipid film.

The absorption of peptides to lipid monolayers is analyzed by calculation of the lateral compressibility of the lipid film, $C_{S}$ $=-1 / A(\partial A / \partial \pi)_{T}$. The observed plateaus in $\pi / A$ isotherms of $\mathrm{CP}_{n} \mathrm{E}$ are converted to peaks in $C_{\mathrm{S}} / \pi$ isotherms. We interpret these plateaus or peaks to be caused by a squeeze out of the peptide material from the monolayer into the subphase, as found previously with untethered peptides $E$ and $K^{22}$

Monolayers Functionalized with $\mathrm{CP}_{n} \mathrm{~K}$. Upon compression of $\mathrm{CP}_{n} \mathrm{~K}$ functionalized monolayers, a uniform surface pressure increase was observed until the membrane collapsed around $\sim 35 \mathrm{mN} / \mathrm{m}$ (Figure 2). The isotherms were shifted to

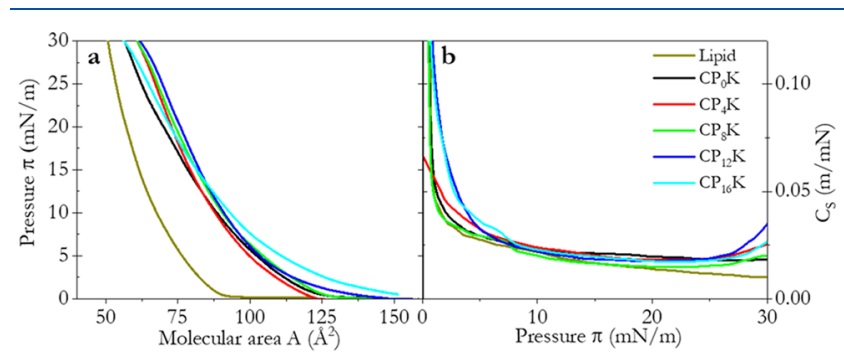

Figure 2. Results of compression experiments with monolayers (lipid composition: DOPC/DOPE/cholesterol as 2:1:1) functionalized with $4 \mathrm{~mol} \% \mathrm{CP}_{n} \mathrm{~K}$. (a) surface pressure $(\pi)$ against molecular area (A), (b) lateral compressibility $\left(C_{S}\right)$ of the lipid film against $\pi$. PBS, $\mathrm{pH} 7.4,20^{\circ} \mathrm{C}$.

higher molecular areas with respect to the pure lipid mixture, indicating the incorporation of $\mathrm{K}$ into the monolayer. Similar results were found for $\mathrm{LP}_{12} \mathrm{~K}$-functionalized monolayers. ${ }^{22}$

These results showed that the anchor and various spacers did not inhibit the peptide-membrane interaction, regardless of their type and length. The compressibility of the lipopeptide-decorated monolayers was found to be slightly increased compared to that of the pure monolayer. The increase in molecular area is similar for all spacer variants and no squeeze out was observed for any variant, although slightly higher values for $A$ were observed for $\mathrm{CP}_{16} \mathrm{~K}$ at low surface pressures and slightly lower values for $A$ were observed for $\mathrm{CP}_{0} \mathrm{~K}$ above a surface pressure $20 \mathrm{mN} / \mathrm{m}$.
Monolayers Functionalized with $\mathrm{CP}_{n} \mathrm{E}$. Upon compression of $\mathrm{CP}_{n} \mathrm{E}$-functionalized monolayers, plateaus were observed at intermediate surface pressures $(15-20 \mathrm{mN} / \mathrm{m})$. Further compression to surface pressures above these plateaus led to isotherms comparable to those of the pure lipid film, as shown in Figure 3. The observed plateaus indicate the squeeze

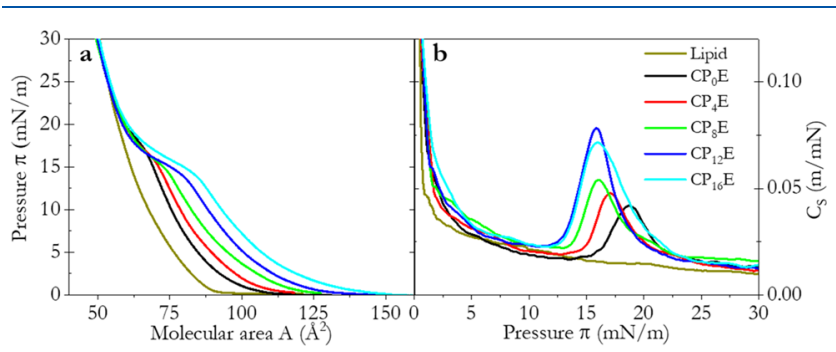

Figure 3. Results of compression experiments with monolayers (lipid composition: DOPC/DOPE/cholesterol as 2:1:1) functionalized with 4 mol \% $\mathrm{CP}_{n}$ E. (a) surface pressure $(\pi)$ against molecular area $(A)$, (b) lateral compressibility $\left(C_{S}\right)$ against $\pi$. PBS, $\mathrm{pH} 7.4,20^{\circ} \mathrm{C}$.

out of $\mathrm{CP}_{n} \mathrm{E}$ upon increasing surface pressure. The reversibility of the squeeze out of $\mathrm{CP}_{n} \mathrm{E}$ is demonstrated by the reversible occurrence of plateaus at the squeeze out pressure $\left(\pi_{\mathrm{SO}}\right)$ during compression and expansion (Figure S1). Calculation of the lost surface area $\left(A_{\mathrm{SO}}\right)$ between 10 and $23 \mathrm{mN} / \mathrm{m}$ reveals that with increasing PEG-spacer length $n$, an increasing amount of molecular area is lost during squeeze out (Table 1 ).

Table 1. Characteristics of Monolayer Experiments, with Standard Lipid Composition and 4 mol \% $\mathrm{CP}_{n} \mathrm{E}$

$\begin{array}{lcrrrc}\text { peptide } & \begin{array}{c}\pi_{\mathrm{SO}}{ }^{a} \\ (\mathrm{mN} / \mathrm{m})\end{array} & \begin{array}{c}A_{\mathrm{SO}}{ }^{b} \\ \left(\AA^{2}\right)\end{array} & \begin{array}{c}A_{\mathrm{SO}}-A^{2}{ }^{c} \\ \left(\AA^{2}\right)\end{array} & \begin{array}{c}A_{\mathrm{PEG}}{ }^{c} \\ \left(\AA^{2}\right)\end{array} & \% \text { incorporated } \\ \mathrm{CP}_{0} \mathrm{E} & 18.8 & 8.1 & -5.7 & 0.6 & 59 \\ \mathrm{CP}_{4} \mathrm{E} & 17.1 & 10.7 & -3.1 & 3.0 & 78 \\ \mathrm{CP}_{8} \mathrm{E} & 16.1 & 14.1 & 0.3 & 5.4 & 100 \\ \mathrm{CP}_{12} \mathrm{E} & 16.0 & 20.9 & 7.1 & 7.8 & 100 \\ \mathrm{CP}_{16} \mathrm{E} & 16.0 & 24.3 & 10.5 & 10.1 & 100\end{array}$

${ }^{a}$ Squeeze out pressures $\left(\pi_{\mathrm{SO}}\right)$ are determined from peak position in $C_{S} / \pi$ graph. ${ }^{b}$ Experimental squeeze out surfaces $\left(A_{\mathrm{SO}}\right)$ were obtained via $\Delta A$ calculation from the $\pi / A$ graphs between 10 and $23 \mathrm{mN} / \mathrm{m}$ with a pure lipid isotherm as the baseline. ${ }^{c}$ Theoretical occupied surface areas of lipopeptides $\left(A_{\mathrm{E}}, 13.8 \AA^{2}\right)$ and PEG spacers $\left(A_{\mathrm{PEG}}\right.$, $\left.0.598(n+1) \AA^{2}\right)$ were obtained via assumption of stiff rod models with appropriate molecular dimensions.

To estimate the occupied surface area of peptide $E$, we assumed a simple model of a stiff rod (diameter $10 \AA$, length $34.5 \AA$, see the Supporting Information (SI)) for its helix. The expected loss of molecular area if all helices are squeezed out is $13.8 \AA^{2}$ for $4 \mathrm{~mol} \%$ lipopeptide. For $\mathrm{CP}_{0}$ and $\mathrm{CP}_{4}$ derivatives, $\Delta A$ is less than expected, implying that, respectively, 59 and $78 \%$ or less of the helices are incorporated. Due to limited degrees of freedom for peptides equipped with a short spacer, a partial incorporation of the helices in the lipid monolayer is reasonable. On the other hand, monolayer-tethered $\mathrm{CP}_{12} \mathrm{E}$ and $\mathrm{CP}_{16} \mathrm{E}$ show an extra contribution in molecular area $\left(A_{\mathrm{SO}}-A_{\mathrm{E}}\right.$ in Table 1). To estimate the theoretical molecular area occupied by a PEG-spacer of length $n$, we assumed a simple molecular model of a stiff rod (diameter $4.15 \AA$, length 3.6 $(n+$ 1) $\AA$, see the Experimental Section). The estimated surface area is in good agreement with the extra contribution found in the lost molecular area. Although PEG is usually regarded as 
inert, it is known to interact with lipid monolayers at low $\pi$ especially when conjugated to a membrane constituent. ${ }^{23-26}$ The observed single peaks in the $C_{S} / \pi$ graph show the simultaneous squeeze out of both spacer and peptide, which demonstrates the interdependent behavior of both during the squeeze out process.

The loss in molecular area for $\mathrm{CP}_{8} \mathrm{E}$ containing monolayers is $14.1 \AA^{2}$. This could be explained in two ways: peptides and spacers both insert partially in the monolayer, or the peptide is completely incorporated in the monolayer, leaving no area for the PEG-spacer. Since there is an energy penalty on solventexposed hydrophobic peptide residues, it is more likely that the peptide fully incorporates in the monolayer, with a solventexposed PEG-spacer. Thus, we conclude that for $\mathrm{CP}_{n} \mathrm{E}$ peptides, elongated PEG-spacers incorporate in the membrane at low surface pressures whereas the PEG-spacer of peptide $\mathrm{CP}_{n} \mathrm{~K}$ stays solvated over the whole pressure range, as shown above.

Increasing the spacer length causes a decrease in squeezed out pressure $\pi_{\mathrm{SO}}$ to $16 \mathrm{mN} / \mathrm{m}$, implying easier squeeze out for those lipopeptides. This indicates a smaller energy gap between low- and high-pressure monolayer states for $\mathrm{E}$ with elongated spacers, compared with lipopeptides with shorter spacers. A decreased energy gap with increasing spacer length could be caused by stabilization of the peptide conformation upon exclusion from the monolayer. A detailed study of the water accessibility of the peptide bonds with IRRAS measurements supports the hypothesis that peptides with elongated PEG spacers can form stabilized homo-oligomers after squeeze out (vide infra).

Monolayers Functionalized with $\mathrm{CP}_{n} \mathrm{E}$ and $\mathrm{CP}_{n} \mathrm{~K}$. As shown in Figure 4, monolayer films decorated with a mixture of $2 \mathrm{~mol} \% \mathrm{CP}_{n} \mathrm{E}$ and $2 \mathrm{~mol} \% \mathrm{CP}_{n} \mathrm{~K}$ show peaks in compressibility at a pressure around $19 \mathrm{mN} / \mathrm{m}$.

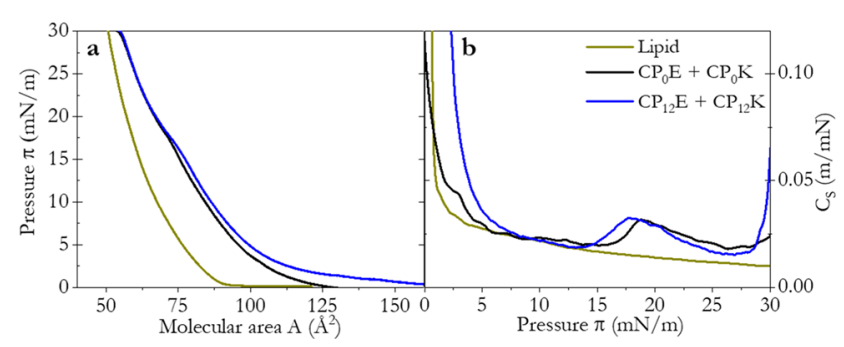

Figure 4. Results of compression experiments with monolayers (lipid composition: DOPC/DOPE/cholesterol as 2:1:1) functionalized with $4 \mathrm{~mol} \% \mathrm{CP}_{n} \mathrm{E} / \mathrm{CP}_{n} \mathrm{~K}(1: 1, n=0,12)$. (a) surface pressure $(\pi)$ against molecular area (A), (b) lateral compressibility $\left(C_{S}\right)$ against $\pi$. PBS, $\mathrm{pH} 7.4,20^{\circ} \mathrm{C}$.

$\Delta A$ calculation showed that a molecular area of $5.2 \AA^{2}$ is still occupied by peptides at a surface pressure of $25 \mathrm{mN} / \mathrm{m}$. It was demonstrated previously that when both peptide $\mathrm{E}$ and peptide $\mathrm{K}$ are present in the proximity of vesicles, peptide $\mathrm{K}$ is in an equilibrium between coiled coil formation with peptide $\mathrm{E}$ and membrane insertion. ${ }^{18}$ Because E-K coiled coils lack the amphipathic nature needed for strong membrane interaction and $\mathrm{E}$ was found to squeeze out at moderate surface pressures, it can be assumed that the increased molecular area compared to that of pure lipid above the squeeze out pressure was solely caused by membrane-immersed peptide $\mathrm{K}$.

Since peptides $\mathrm{E}$ and $\mathrm{K}$ were incorporated in equimolar amounts in the monolayer, a dynamic equilibrium between three hypothetical peptide conformations can be deduced. The increase found in molecular area at high surface pressure, 5.2 $\AA^{2}$, is assumed to be caused by $1.5 \mathrm{~mol} \%$ of membraneembedded peptide $\mathrm{K}$, which corresponds to $1.5 \mathrm{~mol} \%$ of membrane-tethered $\mathrm{E}$ left in a solvated state. The remaining 1 mol \% peptides can be assigned to the $\mathrm{E}-\mathrm{K}$ coiled coil complex. The dynamic equilibrium $[\mathrm{EK}] /([\mathrm{E}]+[\mathrm{K}])=1: 3$, which supports the previous finding that membrane immersion of $\mathrm{K}$ happens concomitant to EK coiled coil formation. ${ }^{20,22}$

IRRAS Measurements. To further study the conformation and the alignment of the peptides with respect to the supporting monolayer, we performed angle- and polarizationdependent infrared reflection absorption spectroscopy (IRRAS) measurements of the described monolayers at the air-water interface. Lipid monolayers containing $4 \mathrm{~mol} \%$ $\mathrm{CP}_{n} \mathrm{E}$ and/or $\mathrm{CP}_{n} \mathrm{~K}$ were prepared on d-PBS buffer $\mathrm{pD} 7.4$ (prepared with pure $\mathrm{D}_{2} \mathrm{O}$ ). $\mathrm{D}_{2} \mathrm{O}$ was used to avoid overlapping contributions of $\mathrm{H}_{2} \mathrm{O}$ vibrations in the amide I spectral region.

An important spectral region to study lipid and peptide properties is between 1600 and $1800 \mathrm{~cm}^{-1}$. In this region, the peptide amide $\mathrm{I}^{\prime}$ band and the lipid $\mathrm{C}=\mathrm{O}$ stretching vibrational band can be found, centered around $\sim 1640$ and $\sim 1735 \mathrm{~cm}^{-1}$, respectively. In all experiments, the intensity of the $\mathrm{C}=\mathrm{O}$ band increases upon monolayer compression due to the increasing lipid density in the IR spot and the relative intensity of the amide $\mathrm{I}^{\prime}$ band $A_{\text {amide I }} / A_{\mathrm{C}=\mathrm{O}}($ short: $\mathrm{AI} / \mathrm{CO})$ is determined to quantify the amount of peptide in the IR spot (Table 2).

IRRA spectra with varying angles of incidence and polarization were recorded at constant surface pressures below and above the observed pressures $\pi_{\mathrm{SO}}$, at 10 and 30 $\mathrm{mN} / \mathrm{m}$, respectively. Fitting of angle- and polarizationdependent spectra yields the order parameter $S$ of the peptide (as described in detail in the SI and refs 34 and 35). The defined orientations of amide bonds in an $\alpha$-helical conformation allows the determination of the angle of the helix axis with respect to the membrane normal, i.e., the peptide angle $\theta . S$ can have values between -0.5 and 1, i.e., parallel or perpendicular to the monolayer plane, respectively. An order parameter of 0 indicates isotropic distribution of the $\mathrm{C}=\mathrm{O}$ bonds and thus that the peptides have a random orientation or a random coil conformation.

Previous studies demonstrated that squeezed out peptides readily leave the measurement spot by dissociation from the air-water interface into the subphase. However, monolayertethered lipopeptides are confined close to the air-water interface and are still detected by the IR beam, even after a peptide squeeze out. ${ }^{22}$ The obtained $\theta \approx 90^{\circ}$ at low surface pressure $(10 \mathrm{mN} / \mathrm{m})$ shows that all peptides are aligned parallel to the monolayer plane before the squeeze out.

Taken together with the results of the compression isotherms, it is evident that the peptides are located between the phospholipids at the air-water interface, most likely with the hydrophobic moment pointing to the hydrophobic region of the monolayer. For monolayers functionalized with $\mathrm{CP}_{0} \mathrm{~K}$ and $\mathrm{CP}_{12} \mathrm{~K}, \mathrm{AI} / \mathrm{CO}$ is similar at both low and high pressure, supporting the hypothesis of incorporation of $\mathrm{K}$ in the monolayer at all pressures. Peptide incorporation at higher surface pressure $(30 \mathrm{mN} / \mathrm{m})$ is further demonstrated by a parallel orientation of the peptide helices of $\mathrm{CP}_{0} \mathrm{~K}$ and $\mathrm{CP}_{12} \mathrm{~K}$ with respect to the monolayer $(S=-0.5)$. These results are in agreement with the characteristics of $\mathrm{LP}_{12} \mathrm{~K}$-decorated 
Table 2. Results of IRRAS Measurements of Monolayers with Unbound Peptides and Monolayer-Tethered Peptides $\mathrm{K}, \mathrm{E}$, and $\mathrm{E}+\mathrm{K}$

\begin{tabular}{|c|c|c|c|c|c|}
\hline monolayer + & $\pi_{\mathrm{SO}}{ }^{a}$ & $\pi$ & $\mathrm{AI} / \mathrm{CO}^{b}$ & $S^{c}$ & $\theta^{d}$ \\
\hline \multirow[t]{2}{*}{$\mathrm{AcK}^{e}$} & 20.5 & 5 & 1.5 & -0.5 & 89 \\
\hline & & 30 & 0.46 & -0.45 & 80 \\
\hline \multirow[t]{2}{*}{$\mathrm{LP}_{12} \mathrm{~K}^{e}$} & 29.5 & 15 & 0.77 & -0.47 & 83 \\
\hline & & 30 & 0.76 & -0.49 & 85 \\
\hline \multirow[t]{2}{*}{$\mathrm{CP}_{0} \mathrm{~K}$} & na & 10 & 0.53 & -0.5 & 90 \\
\hline & & 30 & 0.46 & -0.5 & 89 \\
\hline \multirow[t]{2}{*}{$\mathrm{CP}_{12} \mathrm{~K}$} & na & 10 & 0.44 & -0.5 & 90 \\
\hline & & 30 & 0.48 & -0.5 & 90 \\
\hline \multirow[t]{2}{*}{$\mathrm{AcE}^{e}$} & 7 & 5 & 1.4 & -0.5 & 89 \\
\hline & & 30 & 0 & & \\
\hline \multirow[t]{2}{*}{$\mathrm{LP}_{12} \mathrm{E}^{e}$} & 17.9 & 15 & 0.7 & -0.47 & 82 \\
\hline & & 30 & 0.52 & 0.05 & 53 \\
\hline \multirow[t]{2}{*}{$\mathrm{CP}_{0} \mathrm{E}$} & 18.8 & 10 & 0.74 & -0.48 & 84 \\
\hline & & 30 & 0.24 & -0.13 & 60 \\
\hline \multirow[t]{2}{*}{$\mathrm{CP}_{4} \mathrm{E}$} & 17.1 & 10 & 0.52 & -0.45 & 80 \\
\hline & & 30 & 0.26 & 0.30 & 43 \\
\hline \multirow[t]{2}{*}{$\mathrm{CP}_{8} \mathrm{E}$} & 16.1 & 10 & 0.52 & -0.50 & 90 \\
\hline & & 30 & 0.39 & 0.12 & 50 \\
\hline \multirow[t]{2}{*}{$\mathrm{CP}_{12} \mathrm{E}$} & 16.0 & 10 & 0.67 & -0.50 & 90 \\
\hline & & 30 & 0.3 & -0.15 & 61 \\
\hline \multirow[t]{2}{*}{$\mathrm{CP}_{16} \mathrm{E}$} & 16.0 & 10 & 0.84 & -0.49 & 86 \\
\hline & & 30 & 0.7 & -0.08 & 58 \\
\hline \multirow[t]{3}{*}{$\mathrm{AcE}+\mathrm{AcK}^{e}$} & 9.7 & 5 & 2.68 & -0.5 & 88 \\
\hline & 22.5 & 15 & 1.71 & -0.5 & 89 \\
\hline & & 30 & 0.96 & -0.45 & 80 \\
\hline \multirow[t]{2}{*}{$\mathrm{LP}_{12} \mathrm{E}+\mathrm{LP}_{12} \mathrm{~K}^{e}$} & 18.4 & 15 & 0.87 & -0.47 & 82 \\
\hline & & 30 & 0.62 & -0.15 & 61 \\
\hline \multirow[t]{2}{*}{$\mathrm{CP}_{0} \mathrm{E}+\mathrm{CP}_{0} \mathrm{~K}$} & 18.6 & 10 & 0.43 & -0.5 & 90 \\
\hline & & 30 & 0.31 & -0.23 & 65 \\
\hline \multirow[t]{2}{*}{$\mathrm{CP}_{12} \mathrm{E}+\mathrm{CP}_{12} \mathrm{~K}$} & 17.8 & 10 & 0.78 & -0.5 & 90 \\
\hline & & 30 & 0.57 & 0.02 & 54 \\
\hline
\end{tabular}

${ }^{a}$ Squeeze out pressure $\pi_{\mathrm{SO}}$ obtained by monolayer compression. ${ }^{b}$ Ratio between observed peptide amide I' band and lipid carbonyl band. ${ }^{c}$ Order parameter $S$, calculated by fitting of angle- and polarization-dependent IRRA spectra. ${ }^{d}$ Angle of amide I' moiety with respect to the membrane normal, derived from $S$. ${ }^{e}$ Experiments conducted with monolayers and $\mathrm{AcE} / \mathrm{LP}_{12} \mathrm{E}, \mathrm{K} / \mathrm{LP}_{12} \mathrm{E}+\mathrm{LP}_{12} \mathrm{~K}$ are taken from Rabe et al., 2014. ${ }^{22}$

monolayers. No anchor-induced effect on the peptide structure or the peptide-membrane interaction was found.

For $\mathrm{CP}_{n} \mathrm{E}, \mathrm{AI} / \mathrm{CO}$ decreases significantly upon pressure increase, whereas it stays rather constant for $\mathrm{CP}_{n} \mathrm{~K}$. This observation supports once more the hypothesis that the plateaus in the $\pi / A$ isotherms come along with a significant change in the peptide structure and/or orientation with respect to the incident IR beam. The change in $S$ to values around 0 at $\pi=30 \mathrm{mN} / \mathrm{m}$ supports the squeeze out of all $\mathrm{CP}_{n} \mathrm{E}$ derivatives and indicates that excluded peptides probably have a random orientation of their helix or have random coil conformation.

The equimolar mixture of $\mathrm{CP}_{n} \mathrm{E}$ and $\mathrm{CP}_{n} \mathrm{~K}$ shows ordered peptide structures below the squeeze out pressure. Thus, both peptides $\mathrm{E}$ and $\mathrm{K}$ independently incorporate into the monolayer, since the coiled coil complex lacks an amphipathic nature. The exclusion of peptide $\mathrm{E}$ upon monolayer compression is supported here, by a decrease in $\mathrm{AI} / \mathrm{CO}$ and an increase in $S$. Due to the occurrence of multiple different peptide conformations at high surface pressures, $S$ is an average value that is difficult to interpret.
Amide I' Band Fitting. The position of the amide $\mathrm{I}^{\prime}$ band is highly dependent on the peptide secondary structure and the solvent accessibility of its amide bonds and is thus an important parameter for structure elucidation. ${ }^{27-29}$ For E-K coiled coil peptides, it is known that the amide $\mathrm{I}^{\prime}$ bands observed by IRRAS at intermediate surface pressures $(15 \mathrm{mN} /$ m) consist of a maximum around $1634 \mathrm{~cm}^{-1}$ and a shoulder around $1651 \mathrm{~cm}^{-1}$. 22 The two different band positions are caused by differences in hydrogen bonding of carbonyls buried in the hydrophobic core and solvent accessible carbonyls. ${ }^{28-34}$ Water inaccessible amide bonds absorb at higher wavenumbers $\left(1651 \mathrm{~cm}^{-1}\right)$ than the water accessible ones $\left(1631 \mathrm{~cm}^{-1}\right)$. For membrane-incorporated peptides, these differences in water accessibility of the carbonyls is caused by the alignment of the peptides at the hydrophobic/hydrophilic interface and a partial insertion of hydrophobic side chains into the hydrophobic part of the monolayer. ${ }^{18}$ The band shape of s-polarized spectra is independent of peptide orientation and their intensity scales linearly with the angle of incidence, in contrast to p-polarized spectra. $^{22}$ Thus, the recorded s-polarized spectra were averaged over all angles of incidence (Figure 5) and were fitted with

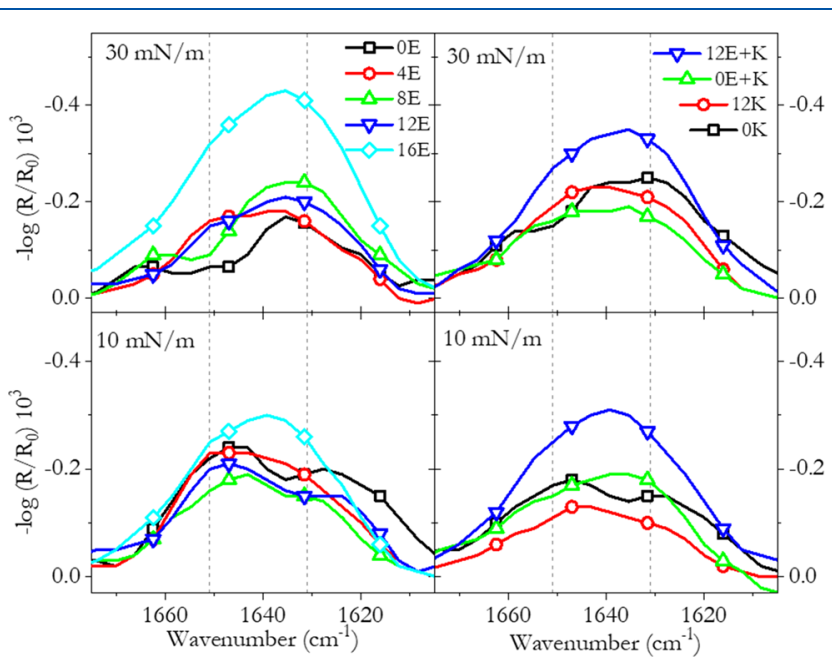

Figure 5. Observed peptide amide I' bands of lipopeptide-decorated monolayers at surface pressures of 10 and $30 \mathrm{mN} / \mathrm{m}$. Peak positions at 1631 and $1651 \mathrm{~cm}^{-1}$ are marked with dotted lines. Monolayers contain $4 \mathrm{~mol} \%$ lipopeptide, $\mathrm{D}_{2} \mathrm{O}$ PBS pD 7.4; angle-averaged spectra are recorded with s-polarized IR light.

three Gaussians at positions around 1631, 1651, and 1672 $\mathrm{cm}^{-1}$, as shown in Figures S12-S19. The nature of the third minor contribution around $1672 \mathrm{~cm}^{-1}$ is unclear; it was assumed previously to be caused by residual TFA from HPLC purification of the lipopeptides ${ }^{35}$ but can also be assigned to Cterminal $\mathrm{CONH}_{2}$ since the absorption occurs consistently in all spectra.

However, the most useful information is conserved in the intensities of the peaks at 1631 and $1651 \mathrm{~cm}^{-1}$. The relative intensity of the peak at $1631 \mathrm{~cm}^{-1}$ (hydrophilic fraction, as a percentage of the total amide I' band intensity) indicates the relative hydrophilicity of the environment of monolayertethered peptides, provided that the secondary structures are similar (Figure 6). Monolayer-incorporated peptides at low pressure show a hydrophilic fraction of $40-50 \%$, which was found for all peptides consistently throughout the compression experiments. At high pressure, however, spacer- and peptide- 


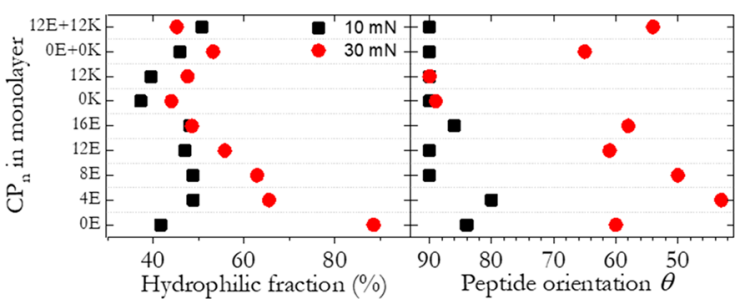

Figure 6. Left: Shape-analysis of amide I' band $\left(1610-1680 \mathrm{~cm}^{-1}\right)$ of lipopeptide-decorated monolayers at surface pressure of $10 \mathrm{mN} / \mathrm{m}$ (black) and $30 \mathrm{mN} / \mathrm{m}$ (red). The amide I' band is fitted with three Gaussians (at 1631, 1651, and $1672 \mathrm{~cm}^{-1}$ ), and the hydrophilic fraction is defined as: (surface area of the Gaussian at $1631 \mathrm{~cm}^{-1}$ )/ (total surface area of amide $I^{\prime}$ band). Right: calculated peptide orientation $\theta$ of monolayer-tethered peptides with respect to the surface normal at surface pressure of $10 \mathrm{mN} / \mathrm{m}$ (black) and $30 \mathrm{mN} / \mathrm{m}$ (red). Monolayers contain 4 mol \% lipopeptide, $\mathrm{D}_{2} \mathrm{O}$ PBS pD 7.4.

dependent trends are visible in the relative hydrophilicity of peptide helices.

For $\mathrm{CP}_{n} \mathrm{~K}$, the hydrophilic fraction is still around $50 \%$ at high pressure, suggesting only minor differences in water accessibility. Also, the overall peptide orientations remain parallel to the membrane upon compression (Figure 6b). These findings are further evidence for membrane-immersed helices of peptide $\mathrm{K}$, with no apparent influence of spacer length $n$.

For E-peptides, the hydrophilic fraction increases at high pressure, which points to a more hydrophilic environment. High solvent exposure of peptides is suggested by a significant decrease of the $1651 \mathrm{~cm}^{-1}$ absorption band, and this is most pronounced for $\mathrm{CP}_{0} \mathrm{E}$-containing monolayers. Remarkably, the hydrophilic fraction at high surface pressure decreases with increasing spacer length such that for $\mathrm{CP}_{16} \mathrm{E}$, the value is similar at both high and low pressures. Since all $\mathrm{CP}_{n} \mathrm{E}$ derivatives are excluded from the monolayer and show order parameters close to 0 at high pressure, we attribute the increasing $1651 \mathrm{~cm}^{-1}$ absorption in the amide $\mathrm{I}^{\prime}$ band to the formation of less water accessible hydrophobic segments of $\mathrm{CP}_{n} \mathrm{E}$ homo-oligomers, ${ }^{33,36}$ which thus becomes more pronounced for elongated spacers. So for this lipopeptide, two trends are observed with increasing PEG-spacer length: first, a decrease in squeeze out pressure and second, a more hydrophobic environment of the squeezed out peptides at high surface pressure. These two observations suggest the increasing of homo-oligomer formation of monolayer-tethered peptide E with increasing PEG-spacer length, at room temperature.
When these results are compared to the reported characteristics of $\mathrm{LP}_{12} \mathrm{E}$, similar values of $\pi_{\mathrm{SO}}$ and $\mathrm{AI} / \mathrm{CO}$ are found for $\mathrm{CP}_{0} \mathrm{E}$ rather than for $\mathrm{CP}_{12} \mathrm{E}$.

For mixtures of $\mathrm{CP}_{0} \mathrm{E}+\mathrm{CP}_{0} \mathrm{~K}$ and $\mathrm{CP}_{12} \mathrm{E}+\mathrm{CP}_{12} \mathrm{~K}$ in the lipid monolayer, the hydrophilic fraction at low and high pressures is close to $50 \%$. This demonstrates that peptide bonds in monolayer-excluded peptides still experience a combined hydrophilic/hydrophobic environment, which is in agreement with the formation of solvated hetero-oligomers. At high surface pressure, orientation changes were found for $\mathrm{CP}_{0} \mathrm{E} / \mathrm{K}$ and $\mathrm{CP}_{12} \mathrm{E} / \mathrm{K}$, which supports a random orientation of solvated heterodimeric coiled coils of $\mathrm{E} / \mathrm{K}$ peptides.

\section{CONCLUSIONS}

In this study, we showed that the peptide-monolayer interaction of the $\mathrm{E} / \mathrm{K}$ fusion model system is affected by the lipid anchor and the length of the conjugated PEG-spacer (Figure 7). Monolayer-tethered peptide $\mathrm{K}$ incorporates in the monolayer up to a surface pressure of $30 \mathrm{mN} / \mathrm{m}$. These peptides are known to incorporate in phospholipid bilayers, due to their amphipathic $\alpha$-helical structure. Slight differences were found between the derivatives; the absence of a spacer hinders full monolayer incorporation, as $\mathrm{CP}_{0} \mathrm{~K}$ endured a partial squeeze out at high surface pressure, although the peptide orientation remained parallel to the monolayer. Remarkably, PEG spacers of $\mathrm{CP}_{n} \mathrm{~K}$ did not incorporate in the membrane at any given surface pressure. No squeeze out was measured for $\mathrm{CP}_{n} \mathrm{~K}$ up to a surface pressure of $30 \mathrm{mN} / \mathrm{m}$, in contrast to $\mathrm{LP}_{12} \mathrm{~K}$, which partially squeezed out at this pressure.

All monolayers functionalized with $\mathrm{CP}_{n} \mathrm{E}$ showed a plateau during compression-expansion cycles, which evidenced the squeeze out of peptide material at high surface pressure. Furthermore, elongated PEG spacers were found to immerse together with the conjugated peptide in the phospholipid monolayer at low surface pressures and were found to promote the formation of homo-oligomers at high surface pressure.

Compression and IRRAS experiments on monolayers containing a mixture of $\mathrm{CP}_{n} \mathrm{E}$ and $\mathrm{CP}_{n} \mathrm{~K}$ support the coexistence of coiled coil structures and membrane-bound peptides.

The length of the PEG spacer of peptide $\mathrm{CP}_{n} \mathrm{~K}$ was found to be the major factor influencing the fusion efficiency of $\mathrm{CP}_{n} \mathrm{E} /$ $\mathrm{CP}_{n} \mathrm{~K}$ decorated liposomes. ${ }^{20}$ We hypothesized that the PEGspacer length $n$ of peptide $\mathrm{K}$ is crucial for efficient fusion by defining the distance between opposing, coiled-coil-connected liposomes. Another possible explanation that the membrane interaction of peptide $\mathrm{K}$ is affected by $n$, thereby influencing

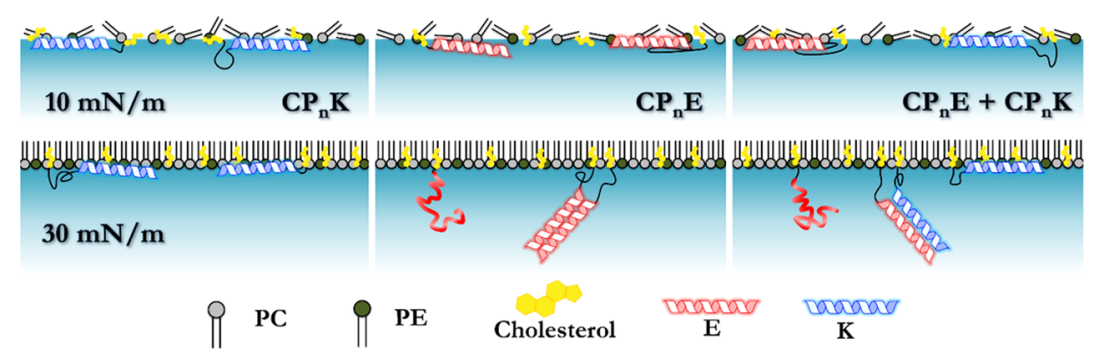

Figure 7. Conformations of lipidated peptides in monolayers: $\mathrm{CP}_{n} \mathrm{~K}$ is immersed in the monolayer at both low and high surface pressure, whereas peptide $\mathrm{CP}_{n} \mathrm{E}$ is expelled upon compression of the lipid monolayer. Compressed monolayers containing a mixture of $\mathrm{CP}_{n} \mathrm{E}$ and $\mathrm{CP}_{n} \mathrm{~K}$ suggest the simultaneous presence of heterodimeric coiled coil (EK), co-existing with individual solvated (E) and membrane-bound (K) peptides. Lipid composition is DOPC/DOPE/cholesterol as 2:1:1. 
the fusion efficiency can now be excluded on the basis of the data presented here. Peptide $\mathrm{CP}_{n} \mathrm{E}$ exhibits a minor enhancement of the fusion process with increasing spacer length. This can be attributed to an increased accessibility of peptides with elongated spacers and/or to the increased tendency of homooligomer formation for peptides with elongated spacers.

\section{ASSOCIATED CONTENT}

\section{S Supporting Information}

The Supporting Information is available free of charge on the ACS Publications website at DOI: 10.1021/acs.langmuir.8b04195.

Isotherms of compression-expansion cycles of $\mathrm{CP}_{12} \mathrm{E} /$ $\mathrm{K}$, detailed description of IRRAS measurements, fitting of angle-dependent spectra, and band shape analysis procedures and the obtained spectra (PDF)

\section{AUTHOR INFORMATION}

\section{Corresponding Author}

*E-mail: a.kros@chem.leidenuniv.nl.

\section{ORCID $\odot$}

Martin Rabe: 0000-0002-0503-5355

Alexander Kros: 0000-0002-3983-3048

\section{Present Address}

"Centre for Research in Biological Chemistry and Molecular Materials, Universidade de Santiago de Compostela, 15782 Santiago de Compostela, Spain (G.A.D.).

\section{Notes}

The authors declare no competing financial interest. We thank Dr. J. Raap for critical reading.

\section{ACKNOWLEDGMENTS}

G.A.D. was funded by The Netherlands Organization for Scientific Research (NWO) via a ChemThem grant to A.K.; C.S. acknowledges the Deutsche Forschungsgemeinschaft (DFG) for financial support (FOR 1145). M.R. acknowledges funding by the European Union's Horizon 2020 research and innovation programme under a Marie Skłodowska-Curie Grant (Agreement No. 705857). A.K. acknowledges the support of a NWO VICI grant (724.014.001).

\section{ABBREVIATIONS}

IRRAS, infrared reflection absorption spectroscopy

\section{REFERENCES}

(1) Chernomordik, L. V.; Kozlov, M. M. Mechanics of membrane fusion. Nat. Struct. Mol. Biol. 2008, 15, 675-683.

(2) Martens, S.; McMahon, H. T. Mechanisms of membrane fusion: disparate players and common principles. Nat. Rev. Mol. Cell Biol. 2008, 9, 543-556.

(3) Yang, Z. W.; Gou, L.; Chen, S. Y.; Li, N.; Zhang, S. L.; Zhang, L. Membrane Fusion Involved in Neurotransmission: Glimpse from Electron Microscope and Molecular Simulation. Front. Mol. Neurosci. 2017, 10, No. 168.

(4) Chen, Y. A.; Scheller, R. H. SNARE-mediated membrane fusion. Nat. Rev. Mol. Cell Biol. 2001, 2, 98-106.

(5) Jahn, R.; Scheller, R. H. SNAREs-engines for membrane fusion. Nat. Rev. Mol. Cell Biol. 2006, 7, 631-43.

(6) Weber, T.; Zemelman, B. V.; McNew, J. A.; Westermann, B.; Gmachl, M.; Parlati, F.; Sollner, T. H.; Rothman, J. E. SNAREpins: Minimal machinery for membrane fusion. Cell 1998, 92, 759-772.

(7) McNew, J. A.; Weber, T.; Parlati, F.; Johnston, R. J.; Melia, T. J.; Sollner, T. H.; Rothman, J. E. Close is not enough: SNARE- dependent membrane fusion requires an active mechanism that transduces force to membrane anchors. J. Cell Biol. 2000, 150, 105117.

(8) Schuette, C. G.; Hatsuzawa, K.; Margittai, M.; Stein, A.; Riedel, D.; Kuster, P.; Konig, M.; Seidel, C.; Jahn, R. Determinants of liposome fusion mediated by synaptic SNARE proteins. Proc. Natl. Acad. Sci. U.S.A. 2004, 101, 2858-2863.

(9) Chan, Y. H.; van Lengerich, B.; Boxer, S. G. Lipid-anchored DNA mediates vesicle fusion as observed by lipid and content mixing. Biointerphases 2008, 3, FA17-FA21.

(10) Marsden, H. R.; Tomatsu, I.; Kros, A. Model systems for membrane fusion. Chem. Soc. Rev. 2011, 40, 1572-1585.

(11) Ries, O.; Loffler, P. M. G.; Rabe, A.; Malavan, J. J.; Vogel, S. Efficient liposome fusion mediated by lipid-nucleic acid conjugates. Org. Biomol. Chem. 2017, 15, 8936-8945.

(12) Löffler, P. M. G.; Ries, O.; Rabe, A.; Okholm, A. H.; Thomsen, R. P.; Kjems, J.; Vogel, S. A DNA-Programmed Liposome Fusion Cascade. Angew. Chem., Int. Ed. 2017, 56, 13228-13231.

(13) Herrmann, A.; Meng, Z.; Yang, J.; Liu, Q.; de Vries, J. W.; Gruszka, A.; Rodríguez-Pulido, A.; Crielaard, B.; Kros, A. Efficient Fusion of Liposomes by Nucleobase Quadruple-Anchored DNA. Chem. - Eur. J. 2017, 9391-9396.

(14) Marsden, H. R.; Korobko, A. V.; Zheng, T. T.; Voskuhl, J.; Kros, A. Controlled liposome fusion mediated by SNARE protein mimics. Biomater. Sci. 2013, 1, 1046-1054.

(15) Yang, J.; Bahreman, A.; Daudey, G.; Bussmann, J.; Olsthoorn, R. C.; Kros, A. Drug Delivery via Cell Membrane Fusion Using Lipopeptide Modified Liposomes. ACS Cent. Sci. 2016, 2, 621-630.

(16) Yang, J.; Tu, J.; Lamers, G. E. M.; Olsthoorn, R. C. L.; Kros, A. Membrane Fusion Mediated Intracellular Delivery of Lipid Bilayer Coated Mesoporous Silica Nanoparticles. Adv. Healthcare Mater. 2017, 6, No. 1700759.

(17) Zope, H. R.; Versluis, F.; Ordas, A.; Voskuhl, J.; Spaink, H. P.; Kros, A. In vitro and in vivo supramolecular modification of biomembranes using a lipidated coiled-coil motif. Angew. Chem., Int. Ed. 2013, 52, 14247-14251.

(18) Rabe, M.; Aisenbrey, C.; Pluhackova, K.; de Wert, V.; Boyle, A. L.; Bruggeman, D. F.; Kirsch, S. A.; Bockmann, R. A.; Kros, A.; Raap, J.; Bechinger, B. A Coiled-Coil Peptide Shaping Lipid Bilayers upon Fusion. Biophys. J. 2016, 111, 2162-2175.

(19) Versluis, F.; Voskuhl, J.; van Kolck, B.; Zope, H.; Bremmer, M.; Albregtse, T.; Kros, A. In situ modification of plain liposomes with lipidated coiled coil forming peptides induces membrane fusion. $J$. Am. Chem. Soc. 2013, 135, 8057-8062.

(20) Daudey, G. A.; Zope, H. R.; Voskuhl, J.; Kros, A.; Boyle, A. L. Membrane-Fusogen Distance Is Critical for Efficient Coiled-CoilPeptide-Mediated Liposome Fusion. Langmuir 2017, 33, 1244312452.

(21) Glasoe, P. K.; Long, F. A. Use of Glass Electrodes to Measure Acidities in Deuterium Oxide. J. Phys. Chem. 1960, 64, 188-190.

(22) Rabe, M.; Schwieger, C.; Zope, H. R.; Versluis, F.; Kros, A. Membrane Interactions of Fusogenic Coiled-Coil Peptides: Implications for Lipopeptide Mediated Vesicle Fusion. Langmuir 2014, 30, 7724-7735.

(23) Winterhalter, M.; Burner, H.; Marzinka, S.; Benz, R.; Kasianowicz, J. J. Interaction of Poly(Ethylene-Glycols) with AirWater Interfaces and Lipid Monolayers - Investigations on Surface Pressure and Surface-Potential. Biophys. J. 1995, 69, 1372-1381.

(24) Gew, L. T.; Misran, M. Interaction between C18 fatty acids and DOPE PEG2000 in Langmuir monolayers: effect of degree of unsaturation. J. Biol. Phys. 2017, 43, 397-414.

(25) Macdonald, R. I. Membrane-Fusion Due to Dehydration by Polyethylene-Glycol, Dextran, or Sucrose. Biochemistry 1985, 24, 4058-4066.

(26) Arnold, K.; Pratsch, L.; Gawrisch, K. Effect of Poly(Ethylene Glycol) on Phospholipid Hydration and Polarity of the External Phase. Biochim. Biophys. Acta, Biomembr. 1983, 728, 121-128.

(27) Barth, A. Infrared spectroscopy of proteins. Biochim. Biophys. Acta, Bioenerg. 2007, 1767, 1073-1101. 
(28) Manas, E. S.; Getahun, Z.; Wright, W. W.; DeGrado, W. F.; Vanderkooi, J. M. Infrared spectra of amide groups in alpha-helical proteins: Evidence for hydrogen bonding between helices and water. J. Am. Chem. Soc. 2000, 122, 9883-9890.

(29) Walsh, S. T. R.; Cheng, R. P.; Wright, W. W.; Alonso, D. O. V.; Daggett, V.; Vanderkooi, J. M.; DeGrado, W. F. The hydration of amides in helices; a comprehensive picture from molecular dynamics, IR, and NMR. Protein Sci. 2003, 12, 520-531.

(30) Brewer, S. H.; Tang, Y. F.; Vu, D. M.; Gnanakaran, S.; Raeigh, D. P.; Dyer, R. B. Temperature Dependence of Water Interactions with the Amide Carbonyls of alpha-Helices. Biochemistry 2012, 51, 5293-5299.

(31) Wang, T.; Lau, W. L.; DeGrado, W. F.; Gai, F. T-jump infrared study of the folding mechanism of coiled-coil GCN4-p1. Biophys. J. 2005, 89, 4180-4187.

(32) Heimburg, T.; Schunemann, J.; Weber, K.; Geisler, N. FTIRspectroscopy of multistranded coiled coil proteins. Biochemistry 1999, 38, 12727-12734.

(33) Rabe, M.; Zope, H. R.; Kros, A. Interplay between Lipid Interaction and Homo-coiling of Membrane-Tethered Coiled-Coil Peptides. Langmuir 2015, 31, 9953-9964.

(34) Pähler, G.; Panse, C.; Diederichsen, U.; Janshoff, A. Coiled-Coil Formation on Lipid Bilayers-Implications for Docking and Fusion Efficiency. Biophys. J. 2012, 103, 2295-2303.

(35) Andrushchenko, V. V.; Vogel, H. J.; Prenner, E. J. Optimization of the hydrochloric acid concentration used for trifluoroacetate removal from synthetic peptides. J. Pept. Sci. 2007, 13, 37-43.

(36) Bulacu, M.; Sevink, G. J. A. Computational insight in the role of fusogenic lipopeptides at the onset of liposome fusion. Biochim. Biophys. Acta, Biomembr. 2015, 1848, 848-858. 